\title{
Psychosocial Problems of Health Migrant Parents and Sick Children
}

\author{
Massimo LM* and Caprino DS
}

Department of Pediatric Hematology and Oncology, G. Gaslini Scientific Children's Hospital, Genova, Italy

*Corresponding author: Luisa M Massimo, Pediatric Hematology and Oncology Unit G. Gaslini Scientific Children's Hospital Largo G, Gaslini 5, 16147 Genova, Italy, Tel: +39-010-591788; E-mail: luisamassimo@ospedale-gaslini.ge.it

Received date: July 20, 2015; Accepted date: September 4, 2015; Published date: September 8, 2015

Copyright: () 2015 Massimo L This is an open-access article distributed under the terms of the Creative Commons Attribution License, which permits unrestricted use, distribution, and reproduction in any medium, provided the original author and source are credited.

\section{Introduction}

For years our Children's Hospital has been one of the reference institutions for children with serious illnesses from several countries that have no public health services or centres of excellence. Most of these children come from the post-Soviet republics, from countries of the southern coast of the Mediterranean, and from Latin America. Following a surge in admissions between 2000 and 2003, the number of hospitalizations is presently quite stable, however, we only admit patients with serious diseases. The social commitments as well as the health care that is needed and the workload for the Institute has become very heavy. There are however, numerous problems that cannot be overcome, especially ones related to language barriers, religion and culture. The mothers of these children, who were away from their families, are unable to develop a coping strategy $[1,2]$.

We have asked to few of the mother to write for us their stories. These mothers are far away from their families and habits, they are alone with their children, they suffer but their relatives discourage them to give up the hope of cure given by the physicians. They experience a loss in their self-monitoring ability to build a coping strategy and resilience. In these cases, their display of anger is often exaggerated. All of these reveal signs of loneliness, stress, pain and anger that are not offset by effective coping strategies and furthermore, they show their inability to build mechanisms of adaptive actions, to elaborate an effective coping strategy and a methodology of resilience. Their cultural backgrounds, as well as the difficulties related to communications are barriers towards building a strong system of selfhelp [3-5].

Anger within is quite a common emotion among many immigrant parents of sick children suffering from high risk diseases who are treated in our hospital for long periods of time. In The majority of these families is housed in communities when not hospitalized, they live together with families from other countries who are of other religions and have different habits. This kind of coexistence is often difficult and can affect their personal and social well-being and generate anger. Self-blame is a common expression of their condition, and they are unable to make helpful self-sacrifices. They feel anger as a result of what has happened to them and they do not have the skills they need to activate a good defence mechanism. In most cases they receive no help from relatives. The anger the children feel also emerges from the mothers' stories because they were taken away from their worlds, their friends, their games. Sick children also feel anger inside towards their mothers, while the mother's anger is directed towards their homeland which does not give health services and does not care about the distress or about the physical and moral difficulties. Their trips are not guaranteed, they have no certainty to be cured.
Everything about the stay is experienced in a traumatic way by the children and their families [6-8].

Resilience is completely unknown to them. This could allow us to act in a positive way when facing adversity, but it does not exist in their culture and it is impossible for them to activate mechanisms that interact between risk and protective factors aimed at achieving a positive result. The linguistic differences and the relationships with the staff of caregivers is an important aspect not only with regard to mutual understanding, but above all, with regard to the lack of true communication which includes the state of mind and attention to the experiences of the child and his family. Unfortunately, neither physicians nor psychologists nor educators may be able to teach them good coping mechanisms. Several psychological and social problems of the immigrant families are an additional problem for physicians and other caregivers working in hospitals that treat immigrant children [9-11].

\section{References}

1. Grootenhuis MA, Last BF (1997) Adjustment and coping by parents of children with cancer: a review of the literature. Support Care Cancer 5: 466-484.

2. Habermas T, Diel V (2010) The emotional impact of loss narratives: event severity and narrative perspectives. Emotion 10: 312-323.

3. Hexem KR, Mollen CJ, Carroll K, Lanctot DA, Feudtner C (2011) How parents of children receiving pediatric palliative care use religion, spirituality, or life philosophy in tough times. J Palliat Med 14: 39-44.

4. Jones PS, Winslow BW, Lee JW, Burns M, Zhang XE (2011) Development of a caregiver empowerment model to promote positive outcomes. J Fam Nurs 17: 11-28.

5. Marshall V, Long BC (2010) Coping processes as revealed in the stories of mothers of children with autism. Qual Health Res 20: 105-116.

6. Massimo LM, Wiley TJ, Baron A, Caprino D (2010) Health inequities and health migration: the high burden paid by an Italian Children's Hospital. Minerva Pediatr 62: 423-424.

7. Massimo LM, Wiley TJ (2010) Seeking treatment abroad. Challenge of migrating patients. BMJ 341: c6665.

8. McCubbin HI, Boss PG, Wilson LR, Dahl BB (1981) Family coping Inventory. In: Mc.Cubbin HI (ed.) Family Assessment Inventories for Research and Practice. University of Wisconsin, Madison, p.635.

9. McCubbin HI, Thompson AI, McCubbin MA (1996) Family assessment: resiliency, coping and adaptation: inventories for research and practice. University of Wisconsin Publishers, Madison.

10. Miedema B, Hamilton R, Fortin P, Easley J, Matthews M (2010) "You can only take so much, and it took everything out of me": coping strategies used by parents of children with cancer. Palliat Support Care 8: 197-206.

11. Senior K (2006) Health migration and childhood cancer. Lancet Oncol 7: 889. 